\title{
Subverting the Rational: An Appreciation of Cave Birds by Ted Hughes
}

\author{
Zhang Pinggong \\ Faculty of English Language and Culture, Guangdong University of Foreign Studies, China
}

Copyright $\subseteq 2018$ by authors, all rights reserved. Authors agree that this article remains permanently open access under the terms of the Creative Commons Attribution License 4.0 International License

\begin{abstract}
This article aims to explore how in the Cave Birds poems Ted Hughes employs innovative poetic strategies to subvert the established and dominant value system of modern humanism and rational determinism. His critical attitude towards dominant value system of secular humanism and scientific determinism is constant, and his criticism about modernity enters a new stage in Cave Birds. The affirmation of what he considers as positive actually involves a good deal of abstraction from the complex predicament of human in modern world. The form of individuality and the wholeness of being that the poet propagates in Cave Birds basically demand a disengagement of consciousness from the outer reality. Through an internal and metaphorical expression of an individual's transformation, his poetic works attempt to defamiliarize the recurrent subject matter of Human-Nature relationship.
\end{abstract}

Keywords Ted Hughes, Subversion, Cave Birds

\section{Introduction}

Many Ted Hughes' poetic works, published from the 1950 s to the 1970 s, are concerned with strong and sometimes violent forces of nature. His mature work is original, skillful and inventive. Especially, his version of the animal world is quite his own, and he projects cruel instincts of them on creatures of his own invention, directing us to the distance of modern society from its vital origins. Hughes writes with great powers of imagination as if from inside the birds and animals who are the subjects of many of his poems, and uses the qualities connected with them in traditional stories as well as observation of how act in real life. His later works witness an enlarged scope of the poet's themes and new dimensions to his criticism of modern Western culture. With consideration of Hughes' critical attitude towards dominant value system of humanism and determinism being constant, it is found that his criticism about modernity enters a new stage in Cave Birds (1978). This collection is a complex set of poems. They reflect that the poet continued to be pre-occupied with the division between the subjective and the objective, between the conscious and the unconscious. The poet's attitude towards the moral and philosophical foundations of the modern world remains unchanged. Cave Birds, as compared with other works by Ted Hughes, lies mainly in the apparent changes that characterize his mood in the poems. Alternatively, Jung's 'individuation' process is essential to a proper reading of Ted Hughes' poems in Cave Birds.

The theory of 'individuation process' or development of "wholeness of being" (Fordham 77) [1] seems to provide the poet with a new mode of responding to the emerging cultural crisis in the West. But the central point of attack in Cave Birds is not merely instrumental rationality. Ted Hughes actually wants to subvert the secular value-system of the modern Western world in its completion. This is why, the poetic representation of Jung's 'individuation process' [2] which in Cave Birds involves a total estrangement from history and society, needs a more critical examination than the critics have generally done by regarding it as the final stage of the poet's spiritual development. Further, the features of mysticism and religiosity that are integral to Ted Hughes's notion of Nature and secular world, in the process of his poetic growth, constantly assume new forms and meanings which have to be carefully defined at each stage of his growth as a poet. The careful examination of the poetic drama of Cave Birds, marks important changes in the poet's mood and his general characterization of Nature which makes this work different in some significant ways from his earlier poems. The poems in Cave Birds are either presented through the persona's own account of his relationship with the social world or through a voice of the poet-narrator. Cave Birds is constantly controlled by a distanced poetic-consciousness which corrects supplements and sometimes, even overturns the meanings projected through the perception of the persona. Nature as a regenerative force is represented by varied symbols. But 
unlike his earlier poems, its emergence and subsequent presence is largely not so aggressive.

\section{Narrow Humanism}

Some important changes in the poet's mood and the mode of Nature's presence in Ted Hughes's poetry demand a close examination of the strategies that suit to the poet's new ideological orientations. With a display of the self-sufficiency of the poet's alternative view of the world, the poems in Cave Birds leave behind the desperation and violent turns which were characteristic of his earlier negations of rationalist humanism and secular modernity. The persona in some of the poems of Cave Birds is not merely a rationalist. Rather he represents the modern sensibility through reliance on the humanism oriented notions of the universe and the scientific or rational modes of cognition. Poems such as "After the First Fright", "In These Fading Moments I Wanted to say", and "The Accused", strongly expose the limitations of the moral order established on the basis of instrumental rationality. These poems carry the ideological overtones of the earlier poems like the Crow poems. But the earlier aggression has largely subsided and the characteristic irony yields to milder forms of satire. The dichotomy between the civilized human world and the universe of Nature is presented with remarkable control and precision.

Beginning with a critique of the complacent rationalist persona, "The Scream" announces the ironic tone of the whole Cave Birds drama: There was the sun on the wallmy childhood's/ Nursery picture. And there my gravestone/Shared my dreams, and ate and drank with me happily. (Three Books 65) In a certain sense, the apparent tone of empathy with the surroundings is misleading. The persona is pleased that the worms in the "ground were doing a good job". However, when he sees the "inane weights of iron / that come suddenly crashing into people, out of nowhere", the indifference with which the poet talks about this issue is not at all reassuring.

It can be felt that the character of the pleasure here is not a form of empathy with Nature in its totality. It is on such occasions when he has vivid glimpses of senseless violence in the universe. Thus, the persona who represents the moral order of the modem world is totally devoid of the basic humanity and sensitiveness that show a genuinely human relationship with the surrounding world. The poet's implicit contention is that the "self-satisfied cosmic generalization," (Gifford and Roberts 205)[3] which asserts its supremacy over the human as well as non-human world, is an instance of narrow humanism. Emphatically asserting that the persona's outlook is a crime deserving severe punishment, this poem implicitly asserts that rationality is a vicious instrument that suppresses the unconscious and natural drives. The poem goes: And his hard life -lust - the blind / Swan of insemination. / And his hard brain - sacred assassin. (Three Books 16) It can be seen from the above cited lines that the poet's discontentment with the patterns of life and experience associated with the Enlightenment humanism is expressed with aggressive overtones. To the poet, the hegemonic status of scientific objectivity and instrumental rationality is basically violence against the laws of Nature. The persona's state of existence and patterns of thinking, as implied in the above lines, are devoid of a genuine respectability towards the non-human universe. But in the scheme of the Cave Birds series, he is in a prepared state necessary for "self-purification, self-purgation and selftransformation." (Hirschberg 156) [4]Some poems clearly indicate the poet's underlying contention that the spiritual transformation of the persona as variously envisaged by the poet cannot coexist with rationality, humanism and a general moral order of a highly modernized Western society. To the poet, these aspects of the contemporary Western society which are dominant in people's consciousness are actually incapable of reviving a social cohesion and individual wholeness of being.

\section{Human-Nature Relationship}

In the collection, such poems as "The Doubtful Charts of Skin" and "In These Fading Moments I Wanted to Say" extend the implication of the newly found attitude of Ted Hughes's poetry. These poems also mark subtle variations in the tone of the speaking voice. The persona, as his rationalist and humanist outlook demands, is quite determined to avoid any actual affinity with the non-human universe and the non-rational part of his own consciousness. "In These Fading Moments I wanted to Say"' irony appears from the persona's assertions. The merging of the modern world and the natural universe constantly exposes the gulf that the persona claims to have overcome: How I cry unutterable outcry / Reading the newspaper and smell of stale refuse / How I just let the excess delight / Spill out of my eyes, as I walk along / How imbecile innocent I am. (Three Books 73) The concluding lines of the poem witness the speaker's increasing obsession with his own perceptions of the external reality. The earlier tone gives way to a detached and emotionally unexcited description. The inherent irony in the evolution of the persona's attitude and claims awakens the reader to the fact that the apparent assertions are basically exaggerations. There are no overt claims but a daring confrontation and acceptance of a new reality. That is why, his "finding weapons in his own grave suggests that he must discover his own subjection to death and that this knowledge strengthens his life." (Gifford and Roberts 213) [5]But this "death' is metaphorical. The whole civilized order comprising the achievements of Enlightenment heritage is finally at stake. The "I" is the representative figure for those who - because they live in 
the world of modern civilization -- have to be subjected to a traumatic experience for the sake of their spiritual regeneration.

Ted Hughes constantly utilizes some mysterious and female figures. These identities as projected by the poet carry immense moral implications. The poems in Cave Birds which celebrate these figures also explicate some aspects of these identities. But violence and certain inclinations are still integral to the poet's view of this figure. Poems such as "The Summoner", "The Interrogator", "The Baptist", "The Judge", "The Executioner" and "She Seemed So Considerate" mainly dwell upon the workings of this force. Its various forms include a female figure, some mysterious birds and the earth itself. While some poems bring out its violent and authoritarian nature, others concentrate mainly upon its regenerative potential. "The Summoner" establishes the identity of an apparently "gangster protectionist": Spectral, gigantified,/ Protozoic, blood-eating/ The carapace/ Of foreclosure/ The cuticle/ Of final arrest. The underlying irony in the titles, as well as the structure of some of these poems, adds to the intensity of subversiveness in the poet's attitude towards the moral and intellectual orientation of the persona. Most of these poems are in third-person narrative style.

It is significant to note that the regeneration of the persona in Cave Birds is essentially dependent upon the ambivalent benevolence of an ahistorical force in whose mode of working death and birth, violence and peace are simply indivisible and unavoidable both as means and consequences. "The Summoner", "The Interrogator", "The Judge" and "The Baptist" serve to scrutinize these claims and these poems show violence as an attribute of a metaphysical and symbolic significance.

"The Summoner" and "The Interrogator" are illustrative in this respect. The use of judicial vocabulary in the title inverts the prevailing and dominant views of crime and punishment, the poet implicitly dismisses the prospects of civility in the judgment. The interrogator is a bird: The bird is the sun's key hole./ The sun spies through. Through her/ He ransacks the camouflage of hunger (Three Books 69)

This metaphorical bird, which is the "blood-louse of Ether" and is troubled by some "angered righteous questions", is quite unmistakable with "her eye on the probe" (Three Books 69). Interrogated by such a figure, the assertive and complacent protagonist of "The Scream" is "as helpless as a skin-and-bone mule trying to hide in a desert but betrayed by the black shadow of its own inescapable physicality". (Sagar 174) [6]Ted Hughes seems to contend that the persona has to admit and accept the punishment that his humanist and rationalist outlook invites for him from the forces of Nature.

There are poems like "The Plaintiff, "She Seemed So Considerate", "The Executioner" and "The Green Mother" which intensify the drama of the sequence and highlight the transforming capabilities of the mysterious and regenerative 'female' figure. The poems in Cave Birds display a balanced reliance on these strategies. The tone of the priestly voice constantly endows a mystic and visionary character to these poems. "The plaintiff refers to the "life-divining bush of your desert" and the "heavy-fruited, burning tree/of your darkness" (Three Books 72). Sometimes, the protagonist is just listening to his own fate. The suppressed non-rational and uncivilized principle of the protagonist's existence is even more effectively dramatized in "She Seemed So Considerate", narrated in the third person. In this poem, the unconscious which puts the individual in touch with Nature in its wild processes comes to the fore. It is confirmed when: But my potted pet fern, the one fellow spirit / I still cherished, / It actually had witnessed./ As if Life had decided to desert me./ As if it saw more hope for itself elsewhere (Three Books 70).

Here the protagonist has undergone a remarkable transformation in his consciousness. But it would be wrong to see this change in the persona's attitude towards this deity in isolation from the all prevailing theme of Man-Nature relationship in Ted Hughes poetry. The state of consciousness that marks the revival of the persona's sensitivity and involvement with the forces of Nature is also to be seen as a state of experience where civilization and history become irrelevant. The calm and mild tone of these poems bespeaks Cave Birds's significant advancement over his earlier poems.

The poems of "The Green Mother" and "The Executioner" make the reader feel the vastness and virtual inaccessibility of the deity. The forces being celebrated in these poems are essentially foreign to the modern consciousness. "The Green Mother" which reveals that the "earth is a busy hive of heaven" (Three Books 87), is primarily a celebration of the heterogeneity of life that earth fosters. The recurrence of the word 'heaven' in the context of flora and fauna demands a metaphorical reading. Though, in the first person narrative and exceptionally emphatic in its convictions, the speaking voice is initially neither of the persona nor of the female or bird-like deity. The concept of a heaven beyond this life is apparently rejected. The trees, flowers, birds, beasts and fish all have their own heavens, but not altogether different from the one the persona has to strive for. The godly voice tells him: These are only some heavens/ Not all within your choice./ These are also the heavens/ Of your persuasion./ Your candled prayers have congealed an angel, a star/ A city of religions. (Three Books 88)

Here the above poem has demystified religion. It foregrounds the richness of life that the earth offers. But this over-emphasis on 'earth' as the sole originator of diverse sorts of heavens is not an affirmation of the modern conditions of life which basically bear the present character of this planet, but of the inherent elements of mysticism and transcendentalism. "The Executioner" 
reads: "It feels like the world/ before your eyes ever opened.... The poem is primarily a critique of secular humanism. And the poet celebrates the centrality of a non-human but intensely mystified source of life in the universe: Fills up/ Sun, moon, stars, he fills them up/ With his hemlock/ They darken/ He fills up the evening and the morning, they darken/ He fills up the sea. (Three Books 75) The presence of 'hemlock' endows the poem with a wider meaning. Thomas West explains this point in these words: "Here with the mention of Hemlock, one senses another drama, historical and concerned with a real, objective world that treats the misfortunes (according to Hughes) of our own culture, so that a cultural as well as a personal renewal is hinted at." (West 84)[7] But whether, individual or collective, this regeneration in Ted Hughes's world-view is firmly rooted in the "incomprehensibility of consciousness" which exists beyond "the shams of personality" (Ibid) [8] as reflected in the modern world.

\section{Alternative Mode of Existence}

The realization of authentic existence made improbable by the dominance of rationalistic thinking and the civilized coverings of the persona's consciousness, is achieved in the poems of Cave Birds where the recovery of mystic reverence for Nature residing in the human as well as the non-human world characterize the persona's behavior. Here, the breach between the subjective and objective worlds that characterized Ted Hughes's poetry at large seems also to have been resolved. These poems do, however, also witness the poet having attained the knowledge which makes the earlier excesses in ideological aggression towards the modern world look unnecessary. Poems such as "Something Was Happening" and "As I Came I Saw a Wood", variously explore the possibilities of mystic and visionary experiences in the human as well as the non-human world. The persona representing the civilized and rationalist consciousness, as reflected in the discussion of the foregoing poems, has finally awakened to a new form of existence which has to be acknowledged and accepted through means other than instrumental rationality.

Ted Hughes, in these poems, seems to suggest that the freshness, openness and humility achieved by the persona are the only substitute for the arrogance and insensitivity that characterized his attitude in his earlier poems. Apparently showing the persona's oneness with the material processes of Nature, the poet indirectly confirms that the more spontaneous urges of non-rational character have now been acknowledged by the persona with all their mystery and forms of mysticism. Overturning the humanistic patterns of thinking in the modem world, these poems celebrate the demise of rationalistic and secularized forms of feeling and thought that were inseparable from the persona's behavior at the beginning of Cave Birds poems. The total evasion of 'history' and social consciousness is essentially integral to the poet's vision of an alternative mode of existence to be reflected through the persona's transformed state of mind.

Such poems as "After There Was Nothing Came a Woman" and "Bride and Groom Lie Hidden for Three Days" mark the culmination of the internal drama of Cave Birds. While celebrating the persona's wholeness of being, both poems subvert the modern world's preoccupation with the rationalistic modes of cognition. Without apparently using any conventional and religious language, the poet explores the consummation of Rung's 'individuation process' by mystifying 'phallic reality' which was also central to the poet's vision of an alternative mode of existence. The poet in "After There Was Nothing Came a Woman" overtly dramatizes the re-emergence of Nature as the Great Goddess of mankind, and the Mother of all life. It is implied in the feminine figure. But this 'she' is the most modest version of the mysterious female figures in Ted Hughes's poetry: She looks at the grass trembling among the worn stones/ Having about as much comprehension as a lamb/ Who stares at everything simultaneously/ With ant-like head and soldierly bearing / She had made it but only just, just (Three Books 93)

Like the whole of Cave Birds, this poem is essentially working at a symbolic level. The narrator who begins with the pretensions of a detached and calm commentator on the events of the objective world, as implied in the tone of the last lines, finally senses mystery and immensity in the action and appearance of 'She'. The use of lamb and ant imagery for highlighting her innocence and distance from what is imagined to be the corrupted and decaying world of civilized and rational man indirectly asserts the continued primacy of the irrational and instinctual mode of existence in the poet's world-view. But as contrasted with this fantastic but emphatic revival of primitivism in symbolic terms, in "Bride and Groom" the poet mainly displays the physical union of the protagonist-lover with his beloved. Using the human body as a machine, the poet suggests through a union of the bodies, a higher spiritual union. She inlays with deep-cuts scrolls the nape of his neck / He sinks into place the inside of her thighs / So, gasping with joy, with cries of wonderment / Like two gods of mud / Sprawling in the dirt, but with infinite care / They bring each other to perfection. (Three Books 98)

The physical union actually carries within it a spiritual renewal and the expression of the 'phallic reality' is merely a reflection of the highest form of consciousness. As Gifford and Roberts observed, "Sexual union is a metaphor for wholeness of being and oneness with the world. It is also both a cause and a consequence of wholeness and unity." (Gifford and Roberts 206)[9] But this form of resolution of the contradictions in Ted Hughes's poetry in general and Cave Birds in particular, suggests the protagonist's gradual entry into an intimate 
and mystical relationship with the world of Nature. Any attempt to explain Ted Hughes's ideal state of existence has to consider the knowledge of the underlying mysticism and religiosity in his poetry. Though apparently at odds with Christianity and other forms of worship, the poet consistently seeks solutions capable of explaining the most ordinary and non-religious events of our individual or collective life. Through a Jungian process of 'individuation', it is evident from the above discussion of Cave Birds that Ted Hughes always lays emphasis on transcendence as a mode of resolution of all kinds of conflicts between opposites.

\section{Conclusions}

It can be discerned that the need to subvert the structure of the established values of the contemporary Western world is inseparable from the fundamental character of the alternative that Ted Hughes projects throughout his poetry. His affirmation of what he considers as positive actually involves a good deal of abstraction from the complex predicament of man in modern world. The form of individuality and the wholeness of being that the poet propagates in Cave Birds basically demand a disengagement of consciousness from the outer reality. His strong naturalistic inclinations correspond to a practical disengagement with the social identity of the individual as well as an overall internalization of meaning in life.

\section{Acknowledgements}

The author wishes to acknowledge gratefully the helpful comment and editorial advice of the anonymous reviewers on this essay.

\section{About the Author}

Zhang Pinggong, Ph.D (Staffs.), currently works at Guangdong University of Foreign Studies in China as Professor of English within the Faculty of English Language and Culture and Researcher at the Center for Foreign Literary and Cultural Studies of GDUFS. His academic interests are related to English Literature and Cultural Studies. Email: 200611570@oamail.gdufs.edu.cn. The author wishes to acknowledge gratefully the helpful comment and editorial advice of the anonymous reviewers on this essay.

\section{REFERENCES}

[1] Fordham, Frieda. An Introduction to Jung's Psychology. New York: Penguin Books, 1981.

[2] Jung, C. Gustav. Memories, Dreams and Reflections. Reissue Edition. London: Vintage, 1989

[3] Gifford, Terry \& Robert, Neit. Ted Hughes: A Critical Study. London: Faber and Faber, 1981.

[4] Hirschberg, Stuart. Myth in the Poetry of Ted Hughes. Dublin: County Dublin Wolfhound Press, 1981.

[5] Gifford, Terry \& Robert, Neit. Ted Hughes: A Critical Study. London: Faber and Faber, 1981.

[6] Sagar, Keith. The Art of Ted Hughes. Cambridge: Cambridge University Press, 1978.

[7] West, Thomas. Ted Hughes. London: Methuen, 1985.

[8] West, Thomas. Ted Hughes. London: Methuen. 1985.

[9] Gifford, Terry \& Robert, Neit. Ted Hughes: A Critical Study. London: Faber and Faber, 1981. 